\title{
The Dynamic Model of EN ISO 52016-1 for the Energy Assessment of Buildings Compared to Simplified and Detailed Simulation Methods
}

\author{
Ilaria Ballarini, Andrea Costantino, Enrico Fabrizio, Vincenzo Corrado \\ Politecnico di Torino, Turin, Italy
}

\begin{abstract}
The research investigates the new hourly method of the assessment of building energy needs for heating and cooling introduced by EN ISO 52016-1. It is compared against both the hourly model of EN ISO 13790 and a detailed dynamic simulation tool (EnergyPlus). The deviations between methods are discussed through a case study. The new method, if properly customized as regards input parameters, provides results close to the detailed simulation, as regards the energy need assessment. The work is aimed at contributing to the normative activity through the validation of the new calculation method, as to enhance its application for the building energy rating.
\end{abstract}

\section{Introduction}

Calculation methods of the building energy performance $(E P)$ are widely used in the regulatory framework, either to check compliance with $E P$ requirements or to carry out the energy performance certification. Among the recently issued technical standards developed within the Mandate M/480 (European Commission, 2010) to support the implementation of Directive 2010/31/EU (European Parliament, 2010), the EN ISO 52016-1 standard (European Committee for Standardisation, 2017b) provides updated calculation procedures of the building energy needs for space heating and cooling. A new hourly model, based on simplified assumptions and a reduced amount of input data compared to a detailed dynamic simulation tool, is introduced.

Many research works deal with the comparison between calculation methods of the building $E P$, usually investigating in what conditions and for which purposes a simplified method can predict with sufficient accuracy the building energy performance if compared with a detailed simulation model. On the other hand, a detailed model still requires a lot of input data that are not always available. According to Millet (2007), simplified simulation methods rely on simple inputs (easy to obtain and understand) and outputs that can be easily checked. In literature, many authors adopted the EN ISO 13790 simple hourly method (European Committee for Standardisation, 2008) to assess the thermal performance of buildings. This method does not considerably increase the computation time if compared with the steady-state method and it does not need further building data to perform the simulation. In addition, the obtained results are usually closer to the ones of detailed simulation tools (Michalak, 2014). Some research works compared the outputs of the simple hourly method with the results of other ones. Kokogiannakis et al. (2008) compared the differences in the energy ratings (both for heating and cooling) that result from using models that are based on the monthly and simple hourly method (EN ISO 13790) and from two detailed simulation tools (EnergyPlus and ESP-r). The analysis was focused on a three-storey building and was carried out considering the variation of some parameters, such as internal heat gains schedules, external walls constructions and climate conditions. The results of this work showed that, in terms of space heating, all methods gave almost the same results, while greater differences stood out in the assessment of space cooling. Michalak (2014) developed a Matlab/Simulink energy model in compliance with the simple hourly method of EN ISO 13790 for the estimation of the annual energy demand for heating and cooling of a twostorey detached house. The outputs of the model were compared with the results of a detailed simulation tool (EnergyPlus) and of the monthly method of EN ISO 13790. The analysis concerned ten different locations (two for each climatic zone of Poland) and demonstrated the reliability of simple hourly method, but pointed out the need of further investigation in the cooling mode. Atmaca et al. (2011) focused on the differences between the simple hourly method and a detailed simulation tool (EnergyPlus) in estimating the heating and cooling energy demand that resulted by varying the thermal capacity of the building envelope. The analysed case study was a single-family house and five different types of external walls were considered. The results of this work enabled Atmaca et al. (2011) to state that the calculation of the building thermal mass of the simple hourly method can be considered reliable in noncomplex buildings. The reliability of the simple hourly method of EN ISO 13790 was confirmed by Costantino et al. (2017) that applied it to livestock houses for estimating the heating and cooling energy needs of a broiler house. The results were compared with the ones of the monthly method and of EnergyPlus. The findings demonstrated that the simple hourly method gave reliable results and was considered suitable for the applications to this specific building type, but slight differences in the estimation of the building thermal mass were pointed out. On the basis of this work, energy simulation models based on simple hourly method were 
developed for the estimation of the heating and cooling energy consumption of livestock houses (Costantino et al., 2018). The results of the models were compared with a dataset of real data and the reliability of the adopted simple hourly method was confirmed.

At present, EN ISO 13790 has been withdrawn and its simple hourly model has been replaced by the new hourly model of EN ISO 52016-1. The research work presented in the paper is aimed at investigating the features of the new method by comparing it against both the hourly model of EN ISO 13790 and the detailed dynamic model of the EnergyPlus simulation tool. General structure, physical principles, required input data and calculation assumptions are highlighted. The calculation methods are applied to a single-family house archetype supposed to be located in Torino (Northern Italy). The resulting deviations, in terms of thermal loads and energy needs for space heating and cooling, and internal operative temperature, are discussed.

A preliminary validation of the new hourly method consistent with BESTEST procedure was carried out by Van Dijk et al. (2016). In the present work, to perform the comparison of the models under the same boundary conditions, consistency options are adopted and some input parameters of EN ISO 52016-1 are calculated in a more accurate way than using the default values of the standard. In addition, a comparison between the building thermal time constants resulting from the three calculation methods is performed to evaluate the effect of the building heat capacity modelling.

The analysis is intended to validate the new calculation method and to investigate whether its use might represent a good compromise between the easiness of the assessment, which is typical of a simplified method, and the accuracy of the results. The work is aimed at contributing to the normative activity by improving the reliability of the new building $E P$ calculation method, as to enhance its application for the energy assessment of buildings.

\section{Calculation methods}

\section{Simple hourly method - EN ISO 13790}

The simple hourly method of EN ISO 13790 is based on the thermal-electrical analogy between the analysed thermal zone and the equivalent 5R1C (5 resistances and 1 capacity) electrical network (Figure 1).

The 5 resistances represent the heat transfer coefficients, in particular the ones due to ventilation $H_{\mathrm{ve}}$, heat transmission $H_{\mathrm{tr}, \mathrm{is}}$, transmission through windows $H_{\mathrm{tr}, \mathrm{w}}$ and through opaque components $H_{\text {trop }}$ that in turn is divided in $H_{\mathrm{tr}, \mathrm{em}}$ and $H_{\mathrm{tr}, \mathrm{ms}}$. The building fabric effective heat capacity $C_{\mathrm{m}}$ is considered concentrated in the only capacity of the equivalent electrical network. The nodes of the network represent the indoor air temperature $\theta_{\text {air }}$, the supply air temperature $\theta_{\text {sup }}$, the outdoor air temperature $\theta_{\mathrm{e}}$, the surface temperature $\theta_{\mathrm{s}}$ and the mass temperature $\theta_{\mathrm{m}}$. The heating/cooling load $\left(\Phi_{\mathrm{H} / \mathrm{C}, \mathrm{nd}}\right)$ is directly applied on the $\theta_{\text {air }}$ node, while the heat flows due to solar radiation and internal sources are considered split into the shares $\Phi_{\mathrm{ia}}, \Phi_{\mathrm{m}}$ and $\Phi_{\mathrm{st}}$ and they are applied on $\theta_{\text {air }}, \theta_{\mathrm{s}}$ and $\theta_{\mathrm{m}}$, respectively.

The electrical network is solved using a finite difference method (Crank-Nicolson scheme) that analyses the 5R1C network with a time discretization of one hour. At each time step $\theta_{\text {air }}$ is calculated as follows:

$$
\theta_{\text {air }}=\frac{H_{\mathrm{tr}, \mathrm{is}} \cdot \theta_{\mathrm{s}}+H_{\mathrm{ve}} \cdot \theta_{\mathrm{sup}}+\Phi_{\mathrm{ia}}+\Phi_{\mathrm{H} / \mathrm{C}, \mathrm{nd}}}{H_{\mathrm{tr}, \text { is }}+H_{\mathrm{ve}}}\left[{ }^{\circ} \mathrm{C}\right]
$$

The $\theta_{\text {air }}$ calculation is repeated twice at each time step, the first time considering free-floating conditions $\left(\Phi_{\mathrm{H} / \mathrm{C}, \mathrm{nd}}=0\right)$ and obtaining $\theta_{\mathrm{air}, 0}$ and the second time considering an heating/cooling load equal to $10 \mathrm{~W} \cdot \mathrm{m}^{-2}$ $\left(\Phi_{\mathrm{H} / \mathrm{C}, \text { nd,10 }}\right)$ and obtaining $\theta_{\mathrm{air}, 10}$. The actual $\Phi_{\mathrm{H} / \mathrm{C}, \text { nd }}$ needed to reach the air set point temperature $\left(\theta_{\mathrm{air}, \mathrm{H} / \mathrm{C}, \mathrm{set}}\right)$ is calculated as follows:

$$
\Phi_{\mathrm{H} / \mathrm{C}, \mathrm{nd}}=\Phi_{10, \mathrm{nd}, 10} \cdot \frac{\theta_{\mathrm{air}, \mathrm{H} / \mathrm{C}, \mathrm{nd}}-\theta_{\mathrm{air}, 0}}{\theta_{\mathrm{air}, 10}-\theta_{\mathrm{air}, 0}}[\mathrm{~W}]
$$

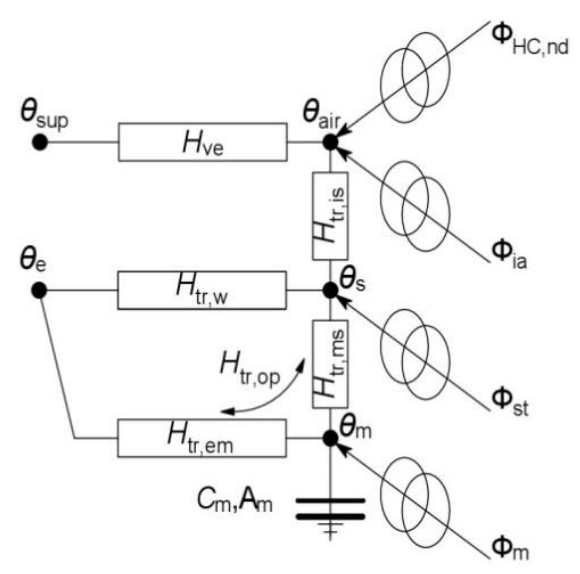

Figure 1: The equivalent 5RIC electrical network behind the simple hourly method of EN ISO 13790.

\section{Detailed dynamic simulation method - EnergyPlus}

EnergyPlus adopts the AHB (Air Heat Balance) algorithm to estimate the heat flow that is needed to maintain the indoor set point temperature inside the analysed enclosure. The AHB assumes the uniformity of the indoor air temperature (perfect mixing), the uniformity of each surface temperature and the uniformity of both long-wave and short-wave radiations. In addition, the conduction heat flow through the building envelope is considered one-dimensional (the effects of thermal bridges are neglected) and the surface irradiation is considered diffuse. Based on the previous assumptions and neglecting the heat transfer due to infiltration and inter-zone air mixing, the AHB reads:

$$
C_{\mathrm{z}} \frac{\mathrm{d} \theta_{\mathrm{z}}}{\mathrm{d} \tau}=\sum_{i=1}^{N} \dot{Q}_{i, \mathrm{c}}+\sum_{i=1}^{N_{\text {sup }}} \dot{Q}_{i, \mathrm{~s}}+\dot{Q}_{\mathrm{V}}+\dot{Q}_{\mathrm{N}}
$$

where $C_{\mathrm{z}}$ is the effective heat capacity of the building internal mass (e.g. furniture) and of the indoor air, $\theta_{\mathrm{z}}$ is 
the air temperature of the thermal zone and $\tau$ is time. $\dot{Q}_{i, \mathrm{c}}$ is the heat flow coming from the $N$ convective heat sources, $\dot{Q}_{i, \mathrm{~s}}$ is the heat flow from the $N_{\text {sup }}$ surfaces of the thermal zone. $\dot{Q}_{\mathrm{V}}$ and $\dot{Q}_{\mathrm{N}}$ are the ventilation heat and HVAC heat loads, respectively.

The heat conduction through the walls is solved using either the finite difference method or the transfer function algorithm, with an hourly time discretization and adopting the "Ideal Load Air System". In this way, infinite heating and cooling loads are provided to the thermal zone and the features of the HVAC system (e.g. efficiencies and maximum capacities) do not affect the results.

\section{Hourly method - EN ISO 52016-1}

As far as the level of detail is concerned, the hourly method of EN ISO 52016-1 stands between a detailed dynamic simulation model and the simple hourly method of EN ISO 13790.

As for EnergPlus, it adopts the AHB algorithm to estimate the heat flow that is needed to maintain the indoor set point temperature inside the analysed enclosure. Nevertheless, some simplifications are added, such as: a simplified distribution of mass in each construction, time-invariant convective/long-wave heat transfer coefficients, and total solar energy transmission directly entering into the zone.

As for the simple method of EN ISO 13790, the hourly method of EN ISO 52016-1 is based on the thermalelectrical analogy between the analysed thermal zone and an equivalent electrical network with one node for the internal air and a few nodes for each construction element. Up to five capacities and four resistances are used for modelling opaque components (Figure 2), and two for windows and doors.

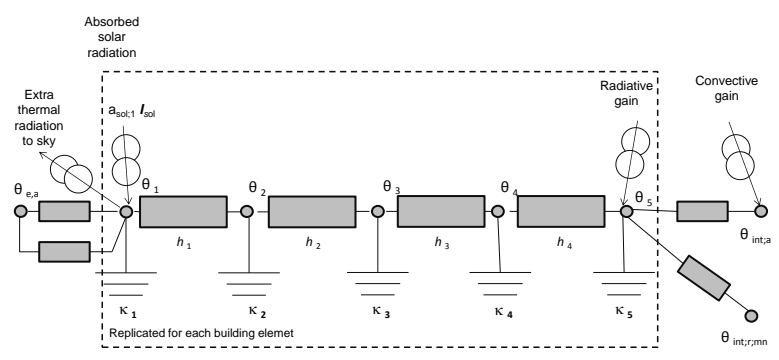

Figure 2: The equivalent " $R C$ " mode of each opaque element behind the hourly method of EN ISO 52016-1.

\section{Application}

\section{Case study description}

The case study is an archetype of a two-storey singlefamily house selected within the IEE-TABULA project (Loga et al., 2012). Its geometry is representative of the single-family house in Northern Italy.

The analysis was carried out for the second storey of the building (Figure 3). The main geometric and construction data of the building storey are shown in Tables 1-3.

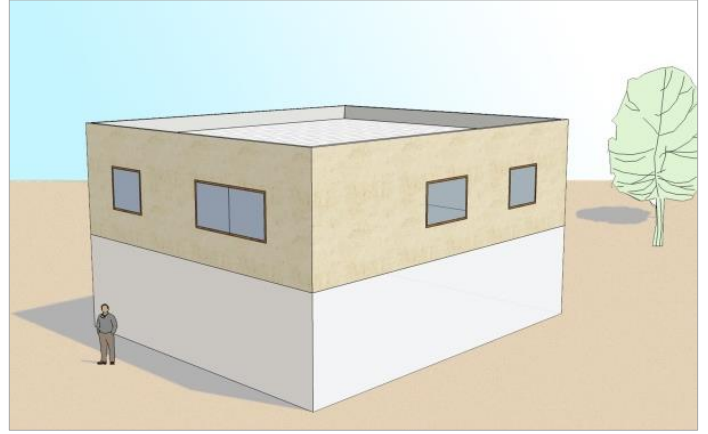

Figure 3: View of the case study model.

Table 3 reports the areal heat capacity that was calculated as:

$$
C=\sum_{i=1}^{N_{\text {layers }}} s_{i} \cdot \rho_{i} \cdot c_{i}\left[\mathrm{~J} \cdot \mathrm{m}^{-2} \mathrm{~K}^{-1}\right]
$$

where, for each $i$-layer of the building component, $s$ is the thickness (in $\mathrm{m}$ ), $\rho$ is the density (in $\mathrm{kg} \cdot \mathrm{m}^{-3}$ ) and $c$ is the specific heat (in $\mathrm{J} \cdot \mathrm{kg}^{-1} \mathrm{~K}^{-1}$ ).

The thermal insulation is placed on the exterior side of external walls and horizontal enclosures. The external opaque surfaces are clear coloured. The windows have double low-e glazing and wood frame, without solar shading devices. As the first storey of the building is conditioned at the same temperature as the second storey, the intermediate floor was assumed adiabatic.

Table 1: Geometric data of the case study.

\begin{tabular}{|c|c|c|}
\hline Quantity & Value & Unit \\
\hline Conditioned gross volume, $V_{\mathrm{g}}$ & 362 & {$\left[\mathrm{~m}^{3}\right]$} \\
\hline Conditioned net volume, $V_{\mathrm{n}}$ & 269 & {$\left[\mathrm{~m}^{3}\right]$} \\
\hline Conditioned net floor area, $A_{\mathrm{f}, \mathrm{n}}$ & 99,5 & {$\left[\mathrm{~m}^{2}\right]$} \\
\hline Compactness ratio, $A_{\text {envelope }} / V_{\mathrm{g}}$ & 0,69 & {$\left[\mathrm{~m}^{-1}\right]$} \\
\hline Windows area, $A_{\text {win }}$ & 12,4 & {$\left[\mathrm{~m}^{2}\right]$} \\
\hline Window-to-wall ratio, $W W R$ & 0,09 & {$[-]$} \\
\hline
\end{tabular}

Table 2: Thermal transmittance of the building envelope components.

\begin{tabular}{|c|c|}
\hline Building envelope component & $\boldsymbol{U}$-value $\left[\mathbf{W} \cdot \mathbf{m}^{-\mathbf{2}} \mathbf{K}^{-\mathbf{1}}\right.$ ] \\
\hline External wall & 0,365 \\
\hline Upper floor (roof) & 0,305 \\
\hline Window & 1,62 \\
\hline
\end{tabular}

Table 3: Areal heat capacity of the building components.

\begin{tabular}{|c|c|}
\hline Building component & $\boldsymbol{C}$-value $\left[\mathbf{k J} \cdot \mathbf{~ m}^{-\mathbf{2}} \mathbf{K}^{-\mathbf{1}}\right.$ ] \\
\hline External wall & 273 \\
\hline Internal wall (partition) & 65,5 \\
\hline Upper floor (roof) & 342 \\
\hline Intermediate floor & 204 \\
\hline
\end{tabular}

\section{Boundary conditions and simplifying assumptions}

Hourly schedules of the sensible internal heat gains and natural ventilation flow rate were defined for workdays and weekends, distinguishing between occupied and unoccupied periods. The weekly mean value of internal gains is $5,4 \mathrm{~W} \cdot \mathrm{m}^{-2}$ and $0,4 \mathrm{~h}^{-1}$ of ventilation air change; both refer to a standard residential use. Continuous thermal system operation with a dead-band thermostat, 
with lowest limit at $20{ }^{\circ} \mathrm{C}$ (heating mode) and highest limit at $26^{\circ} \mathrm{C}$ (cooling mode), was considered.

The building is located in Torino (Italy). The test reference year database of the Italian Thermotechnical Committee (2016) was used as source of hourly weather data.

To carry out a preliminary comparison of the calculation methods, some boundary aspects and modelling options were excluded from the numerical simulations by adopting the following simplifying assumptions:

- building envelope without thermal bridges,

- neither ground nor unconditioned rooms as boundary spaces,

- absence of external obstructions.

\section{Consistency options}

Consistency options were adopted in the three models to make their results comparable. Some input parameters of EN ISO 52016-1 were calculated in a more accurate way and differently from the default values of the standard as to allow the comparison with the detailed dynamic simulation. In this way, the deviations with respect to EnergyPlus are assessed on the basis of the modelling options and not of the input data.

The adopted consistency options are listed and described as follows.

1. Heating and cooling set-point temperatures. Heating and cooling set-points for all models are referred to the operative temperature.

2. Sky temperature. The extra thermal radiation to the sky was modelled considering $11 \mathrm{~K}$ difference between the apparent sky temperature and the air temperature, as specified in EN ISO 52016-1.

3. Convective and radiative fractions of heat flows. In all models, the heat supplied by heating and cooling systems to the thermal zone was set completely convective, while the heat flow from internal sources was assumed $40 \%$ convective and $60 \%$ radiative.

Other modelling options were just partially made consistent, due to the different calculation structure and principles of the three methods. This occurs in the assessment of the solar heat gains and of the building thermal capacity.

A different modelling of the solar heat gains is performed by the analysed dynamic methods. EnergyPlus splits the solar radiation incident on the window into the fraction directly transmitted into the zone, and that one absorbed inside the glass panel and then re-emitted inside the thermal zone. On the other hand, the EN ISO 52016-1 and 13790 methods evaluate a global amount of solar gains through windows into the zone by applying the total solar energy transmittance of glazing $\left(g_{\mathrm{gl}}\right)$. EN ISO 52016-1 requires that, for windows with non-scattering glazing, the $g_{\mathrm{gl}}$-value is calculated by correcting the total solar energy transmittance at normal incidence $\left(g_{\mathrm{gl}, \mathrm{n}}\right)$ by a factor $\left(F_{\mathrm{w}}\right)$ that takes into account the effective incidence angle of solar radiation. This correction factor was calculated on hourly basis as a function of the incidence angle, and applying the empirical model developed by Karlsson and Roos (2000).

The calculation methods implement different models to take into account the building thermal capacity. In the present work, in EnergyPlus, external walls, roof and intermediate floor were geometrically modelled and the finite difference heat conduction model was applied. Internal vertical partitions were modelled considering the thermo-physical properties of the internal walls layers and the area exposed to internal air. The partitions interact convectively and radiatively with the zone air and the other surfaces of the zone.

In EN ISO 52016-1, the building components were modelled as well. Following Table 3 , the heat capacity of each envelope component was applied to the internal surface node, in accordance with the mass position class (Class I - mass concentrate at the internal side) defined in EN ISO 52016-1 - Annex B. In both dynamic models, furniture heat capacity was applied on the air node.

In the EN ISO 13790 hourly model, the building internal heat capacity (concentrated in the only capacity of the equivalent electrical network) was calculated as the summation of the internal effective heat capacity of both envelope components and internal partitions. This quantity was assessed by means of the thermal admittances method, in accordance with EN ISO 13786 (European Committee for Standardisation, 2017a). The heat capacities of air and furniture were added as well.

As the analysis has been focused on the assessment of the thermal loads for space heating and space cooling, the effects of specific technical building systems were not considered and an ideal system operating with an infinite heating/cooling capacity was applied in the three calculation models.

\section{Results and discussion}

\section{Thermal energy needs}

The yearly heating and cooling energy needs that were obtained through the energy simulation are presented in Table 4. The simple hourly simulation models give similar results in terms of energy needs if compared with EnergyPlus. The EN ISO 13790 method overestimates the yearly heating need by $2,0 \%$, while the $\mathrm{EN}$ ISO 52016-1 simulation underestimates it by $4,7 \%$. Both simplified hourly simulations overestimate the cooling needs, but this overestimation is greater in EN ISO $13790(4,1 \%)$ than in EN ISO 52016-1 (0,3\%).

Table 4: Yearly heating and cooling energy needs.

\begin{tabular}{|c|c|c|}
\hline $\begin{array}{c}\text { Simulation } \\
\text { model }\end{array}$ & $\begin{array}{c}\text { Yearly heating } \\
\text { energy need }\end{array}$ & $\begin{array}{c}\text { Yearly cooling } \\
\text { energy need }\end{array}$ \\
\hline EnergyPlus & $5345 \mathrm{kWh}$ & $1689 \mathrm{kWh}$ \\
\hline EN ISO 52016-1 & $5096 \mathrm{kWh}$ & $1694 \mathrm{kWh}$ \\
\hline EN ISO 13790 & $5452 \mathrm{kWh}$ & $1758 \mathrm{kWh}$ \\
\hline
\end{tabular}

In Figure 4, monthly energy needs for heating and cooling from the three models are shown. Both simplified hourly methods provide results that are close 
to the ones of EnergyPlus. The maximum absolute difference in terms of heating needs, normalised on the net floor area, is $0,85 \mathrm{kWh} \cdot \mathrm{m}^{-2}$ for EN ISO $52016-1$ (December) and $0,55 \mathrm{kWh} \cdot \mathrm{m}^{-2}$ for EN ISO 13790 (October) if they are compared with EnergyPlus. The maximum absolute difference in terms of cooling need is $0,29 \mathrm{kWh} \cdot \mathrm{m}^{-2}$ for EN ISO 52016-1 (September) and $0,64 \mathrm{kWh} \cdot \mathrm{m}^{-2}$ for EN ISO 13790 (May). Figure 4 shows that, in the heating season, the EN ISO 52016-1 model generally underestimates the heating need if compared with EnergyPlus, with the only exceptions of March and April. Nevertheless, the underestimation is slight also in relative terms, being the maximum difference with the EnergyPlus simulation equal to $7 \%$ in October. On the contrary, EN ISO 13790 generally provides greater values of heating needs if compared with EN ISO 52016-1 and with EnergyPlus outputs too. This trend is evident in May, because the EnergyPlus simulation and the EN ISO 52016-1 one do not estimate significant heating needs ( 1 and $3 \mathrm{kWh}$, respectively), while the EN ISO 13790 simulation estimates a heating need of $33 \mathrm{kWh}$. This difference may be due to the ways in which the EN ISO 13790 model takes into account the effective heat capacity of the building, $C$.

\section{Heat capacity}

For assessing the differences in the estimation of $C$, an analysis concerning the building thermal time constant $\tau$ was carried out. The thermal time constant can be defined following the equation that represents the thermal decay of the temperature of a lumped monocapacitive system when outdoor temperature is constant:

$$
\theta_{\mathrm{op}}(t)=\theta_{\mathrm{e}}+\left(\theta_{\mathrm{op}, \mathrm{set}}-\theta_{\mathrm{e}}\right) \cdot e^{-\frac{t}{\tau}}\left[{ }^{\circ} \mathrm{C}\right]
$$

where $\theta_{\mathrm{op}}$ is time $(t)$ dependent indoor operative temperature, $\theta_{\mathrm{op}, \mathrm{set}}$ is the initial indoor temperature, $\theta_{\mathrm{e}}$ is the constant external air temperature. $\tau$ is therefore the time that the difference between the indoor operative temperature and the outdoor air temperature (considered constant) takes to decrease up to a $1 / e$ factor. Even though this is a simplifying approach based on a monocapacity building, it was used to retrieve in the various models a quantification of $\tau$ and $C$. In fact, $\tau$ can be expressed as a function of the building parameters as:

$$
\tau=\frac{C}{3600 \cdot H_{\text {tot }}}[\mathrm{h}]
$$

where $C$ is the heat capacity (in $\mathrm{J} \cdot \mathrm{K}^{-1}$ ) and $H_{\text {tot }}$ is global heat transfer coefficient (in $\mathrm{W} \cdot \mathrm{K}^{-1}$ ) of the thermal zone.

To compute the building thermal time constant $\tau$ in the three different simulations (that relay on a different estimation of the building heat capacity), a simulation run was performed with the following assumptions:

- initial $\theta_{\mathrm{op}}$ stabilized and equal to $20^{\circ} \mathrm{C}$,

- $\theta_{\mathrm{e}}$ constant and equal to $0^{\circ} \mathrm{C}$,

- no internal heat gains or solar gains,

- no ventilation or infiltration heat exchange (to maximize the sensitivity of the variation to the heat capacity in the various models).

Temperature decays and $\tau$-values are shown in Figure 5 . While EnergyPlus and EN ISO 52016-1 give similar results (296 h and $233 \mathrm{~h}$, respectively), EN ISO 13790 provides a lower value $(81 \mathrm{~h})$.

\section{Heating and cooling loads}

The main difference between the fully physical based hourly model and the simplified hourly model is in the time shift of the hourly thermal loads. This affects the required thermal load to the system, which in turn affects the required energy carriers delivered or produced onsite with mismatching problem.

In Figure 6, the estimated hourly heating loads (from the three models) during the $2^{\text {nd }}$ week of January (cold season) are plotted on the primary axis, while the estimated operative temperatures (from the three models) are plotted on the secondary axis with the outdoor air temperature. During the considered period, heating loads are always needed for maintaining the indoor set point temperature, with only two exceptions on January $10^{\text {th }}$ and $14^{\text {th }}$, for both simplified hourly simulations. This difference may be explained considering the outdoor air temperature peaks that characterize these days. The sudden increase in the outdoor air temperature has a larger influence on the indoor operative temperature estimated by the simple hourly models due to their building time constants that, above all in EN ISO 13790, are shorter than the one of EnergyPlus. The influence of the building thermal time constant is also evident between January $11^{\text {th }}$ and $13^{\text {th }}$ when the temperature variations between day and night are greater than before. In this period, the heating loads that are estimated during the night by the EN ISO 13790 simulation are higher than the ones from the EN ISO 52016-1 and EnergyPlus simulations. This pattern may be due to the higher values of the building thermal time constants of the EN ISO 52016-1 and EnergyPlus simulations that enable the building to use more the heat stored in the building fabric when outdoor air temperatures decrease during the night. In this way, lower heating loads should be provided by the HVAC system. During the day the pattern is the opposite. Even though the outdoor air temperatures during day are higher, EN ISO 52016-1 and EnergyPlus estimate greater heating loads because the high values of the effective building fabric heat capacity makes the building less sensitive to weather variations.

A similar trend can be identified also in Figure 7, where the estimated hourly cooling loads are plotted on the primary axis of the chart during the $3^{\text {rd }}$ week of July (warm season). During this period, the cooling load that is estimated by the EN ISO 13790 model during the day is always higher than the one from EN ISO 52016-1 and EnergyPlus. During nights, this trend is the opposite, because both simplified models estimate a cooling load that is almost zero.

The time shift of thermal loads between the simplified models and EnergyPlus is evident despite the input data and modelling options were made consistent. This 
behaviour may depend on the difference in the building thermal time constant. The greater thermal time constant of the EnergyPlus simulation entails the need to remove the stored heat in the building components during the night, while this need is not present in the other models with lower values of the building thermal time constants.

\section{Free-floating temperature}

In Figure 8, the free-floating indoor operative temperatures for the three models are plotted with the outdoor air temperature (from October $1^{\text {st }}$ to $12^{\text {th }}$ ). The indoor operative temperatures that are estimated by EN ISO 52016-1 and EnergyPlus are similar. To evaluate numerically the reliability of the models on the estimation of the operative temperature during freefloating period, the Root Mean Square Error (RMSE), the Mean Bias Error $(M B E)$ and the Coefficient of Variation of RMSE ( $C v(R M S E))$ were calculated, as:

$$
\begin{aligned}
& R M S E=\sqrt{\frac{\sum_{i=1}^{N_{i}}\left(\theta_{\text {simpl }, i}-\theta_{\text {EPlus }, i}\right)^{2}}{N_{i}}}\left[{ }^{\circ} \mathrm{C}\right] \\
& M B E=\frac{\sum_{i=1}^{N_{i}}\left(\theta_{\text {Simpl. }, i}-\theta_{\text {EPlus }, i}\right)}{\sum_{i=1}^{N_{i}} \theta_{\text {EPlus }, i}} \cdot 100[\%] \\
& C v(R M S E)=\frac{R M S E}{\frac{1}{N_{i}} \sum_{i=1}^{N_{i}} \theta_{\text {EPlus }, i}} \cdot 100[\%]
\end{aligned}
$$

where $\theta_{\mathrm{EPlus}, i}$ is the indoor operative temperature from EnergyPlus at time step $i, \theta_{\text {simpl., } i}$ represents that value to compare (from EN ISO 52016-1 or EN ISO 13790) at time step $i$, and $N_{i}$ is the number of considered time steps (288 hours). RMSE is a good index for the reliability of the estimation, while $M B E$ and $C v(R M S E)$ can be compared with the ASHRAE thresholds of Guideline 14 (ASHRAE, 2014). The results of these calculations are reported in Table 5. The EN ISO 13790 simulation is characterized by worse reliability indexes if compared with the EN ISO 52016-1 ones, but both simplified hourly methods can be considered reliable for this

\begin{tabular}{|c|c|c|c|}
\hline & $R M S E$ & $M B E$ & $C v(R M S E)$ \\
\hline EN ISO 52016-1 & $0,21{ }^{\circ} \mathrm{C}$ & $0,2 \%$ & $0,9 \%$ \\
\hline EN ISO 13790 & $1,16^{\circ} \mathrm{C}$ & $-4,2 \%$ & $4,7 \%$ \\
\hline Threshold & - & $\pm 10 \%$ & $30 \%$ \\
\hline
\end{tabular}
application.

Table 5: Evaluation of the reliability of the models in the

\section{Conclusion}

In this work, the main differences between the simple hourly method of EN ISO 13790 and the new hourly method of EN ISO 52016-1 are shown. Two simulation tools in compliance with the previously mentioned methods were developed and applied to the same case study. The results were compared with the outputs of an EnergyPlus simulation. All methods take into account the influence of hourly and daily variations in weather, operation (thermostats, occupancy etc.) and their dynamic interactions with heating and cooling loads.

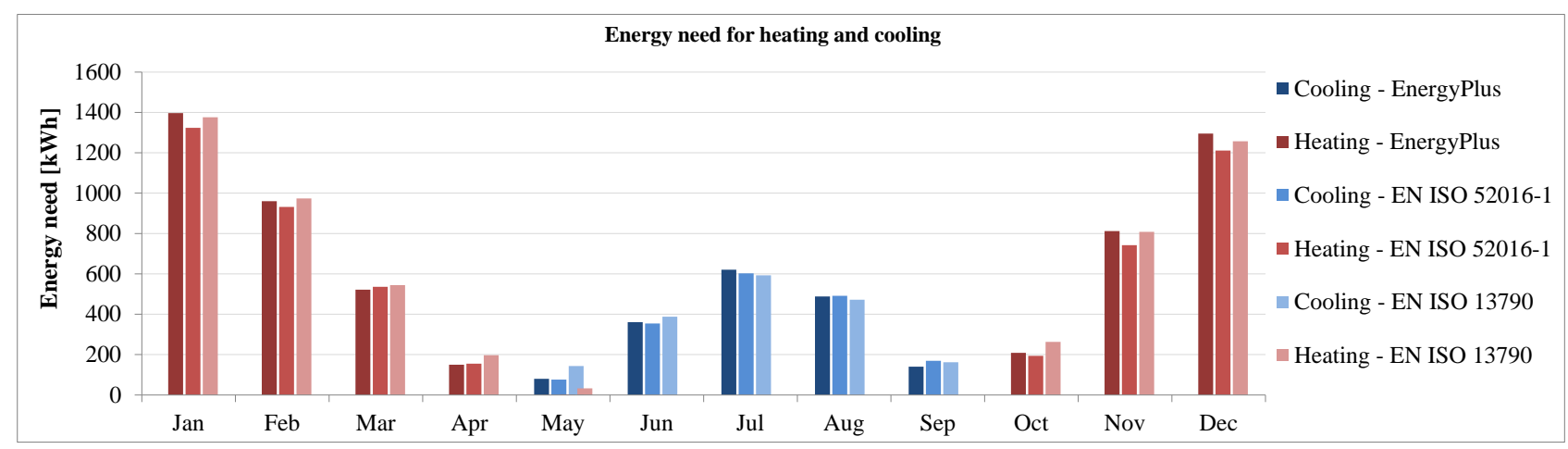

Figure 4: Comparison between the estimated monthly energy needs for heating and cooling.

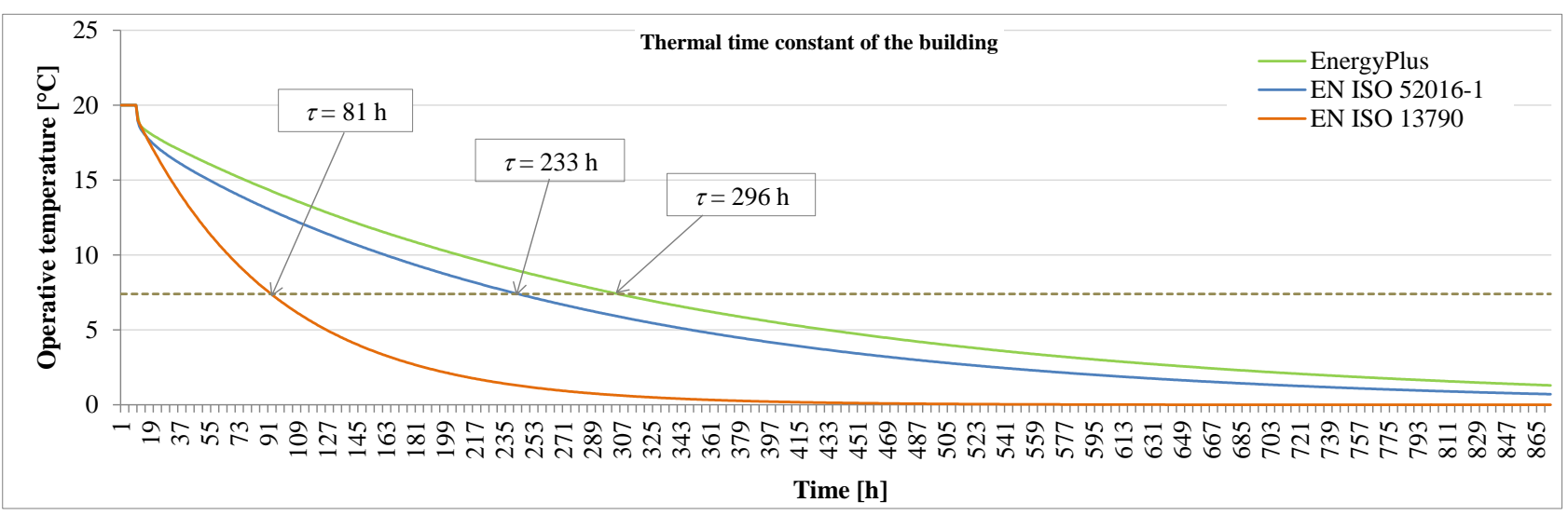

Figure 5: Comparison between the thermal time constants of the building derived from simulation. 


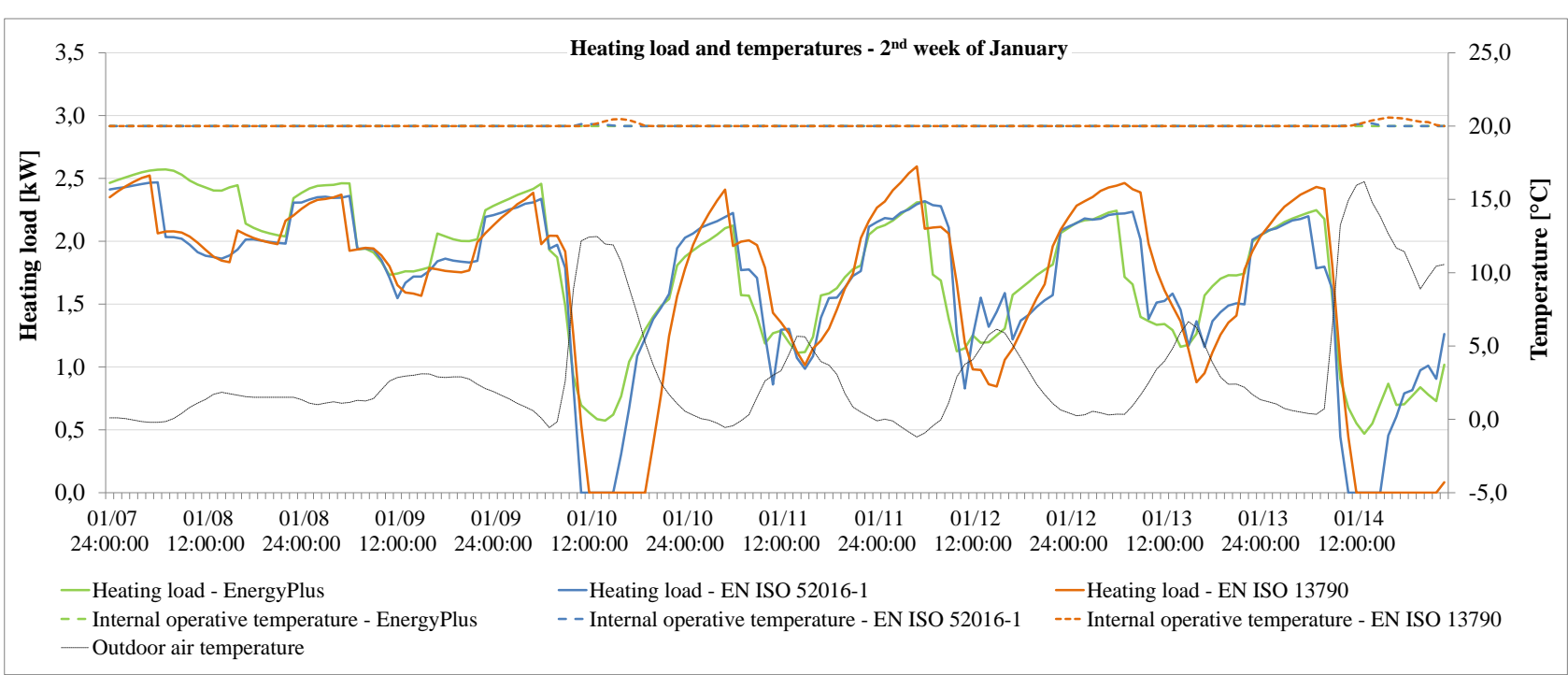

Figure 6: Comparison between the heating loads from the three simulation models.

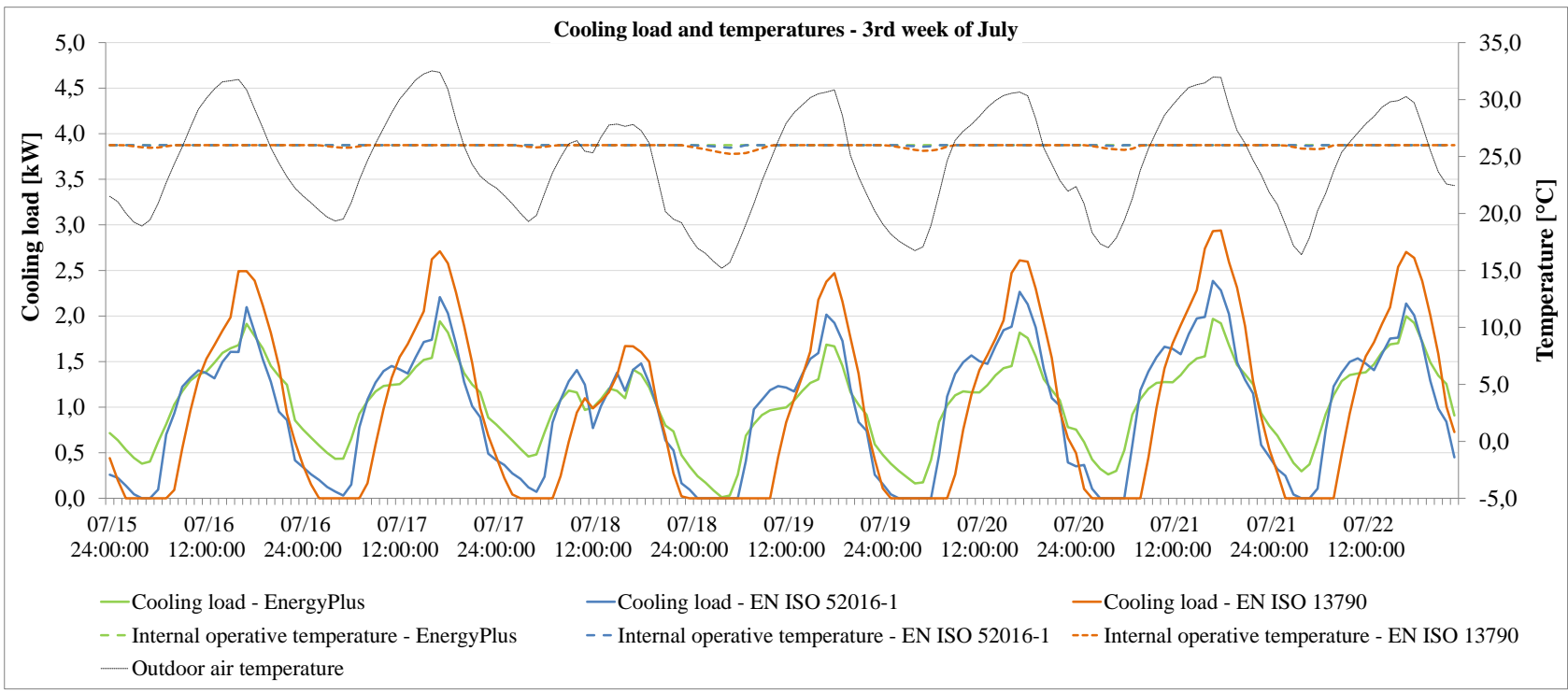

Figure 7: Comparison between the cooling loads from the three simulation models.

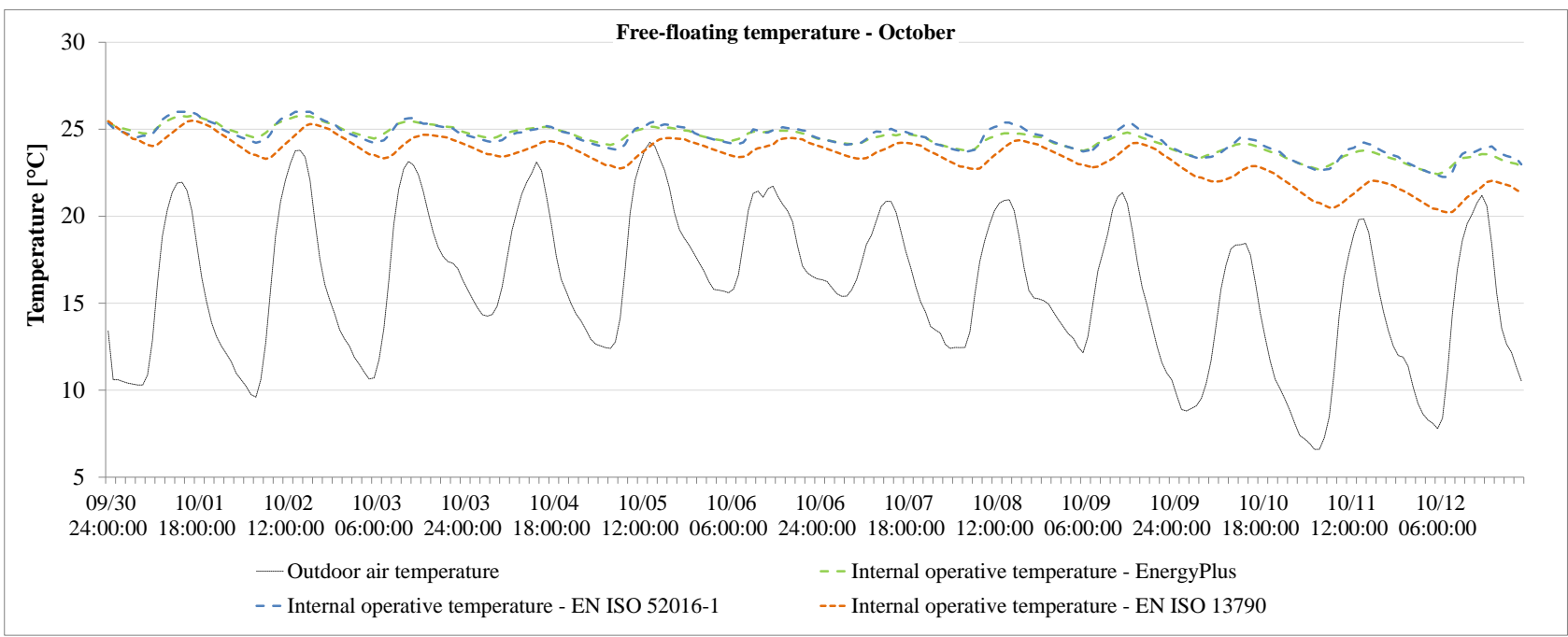

Figure 8: Comparison between free-floating indoor operative temperatures from the three simulation models. 
The advantages in the use of the hourly model of EN ISO 52016-1 compared to the others are noticeable, and can be summarised in the following:

- use of a smaller amount of input data compared to a detailed tool,

- more advanced and reliable calculation method compared to that provided by EN ISO 13790, due to a more detailed modelling of the resistance-capacity network of the building envelope components,

- more transparent and widely usable model compared to detailed dynamic simulation tool.

The main difference between the analysed simulation methods concerns the effective heat capacity of the building and, consequently, the building thermal time constant into each simulation model. The value of the building thermal time constant estimated according to the hourly method of EN ISO 52016-1 is more similar to the one of a detailed dynamic simulation (EnergyPlus).

The hourly method of EN ISO 52016-1, properly customized as regards input parameters, demonstrated to provide results that are more similar to the ones of a detailed dynamic simulation (EnergyPlus) if compared to the hourly method of EN ISO 13790. Nevertheless, both simplified methods may be considered reliable for the energy needs assessment of simple case studies, as the one presented in this work. As regards the thermal loads, the time shift between the EN ISO 52016-1 and the EnergyPlus models is evident despite the input data and modelling options were made consistent.

A further deepening of this work will regard the adoption of the same building thermal time constant for all the performed simulations. Further analyses should address the reliability of EN ISO 52016-1 with more complex case studies characterised by different boundary conditions and effective heat capacities. For the application of this method in a legislative framework (e.g. building energy rating), a comparison with other simulation methods on the basis of the energy ratings that are obtained as outputs should be carried out.

\section{References}

ASHRAE (2014). Measurement of Energy, Demand, and Water Savings (Guideline 14).

Atmaca, M., Kalaycioglu, E., Yilmaz, Z. (2011). Evaluation of the heating \& cooling energy demand of a case residential building by comparing the national calculation methodology of Turkey and EnergyPlus through thermal capacity calculations. Technical Report. Energy Systems Laboratory, Texas A\&M University.

Costantino, A., Fabrizio, E., Ghiggini, A., Bariani, M. (2018). Climate control in broiler houses: A thermal model for the calculation of the energy use and indoor environmental conditions. Energy and Buildings 169, 110-126.

Costantino, A., Ballarini, I., Fabrizio, E. (2017). Comparison between simplified and detailed methods for the calculation of heating and cooling energy needs of livestock housing: a case study. Proceedings from $3^{\text {rd }}$ IBPSA Conference Italy. Bozen-Bolzano (Italy), 8-10 February.

European Commission (2010). M/480 EN, Mandate to CEN, CENELEC and ETSI for the elaboration and adoption of standards for a methodology calculating the integrated energy performance of buildings and promoting the energy efficiency of buildings [...].

European Committee for Standardisation (2008). Energy performance of buildings - Calculation of energy use for space heating and cooling (ISO 13790).

European Committee for Standardisation (2017a). Thermal performance of building components Dynamic thermal characteristics - Calculation methods (ISO 13786).

European Committee for Standardisation (2017b). Energy performance of buildings - Energy needs for heating and cooling, internal temperatures and sensible and latent heat loads - Part 1: Calculation procedures (ISO 52016-1).

European Parliament (2010). Directive 2010/31/EU of the European Parliament and of the Council of 19 May 2010 on the energy performance of buildings (recast).

Italian Thermotechnical Committee (2016). Test reference years for thermotechnical applications. http://try.cti2000.it/

Karlsson, J., Roos, A. (2000). Modelling the angular behaviour of the total solar energy transmittance of windows. Solar Energy 69, 321-329.

Kokogiannakis, G., Strachan, P., Clarke, J. (2008). Comparison of the simplified methods of the ISO 13790 standard and detailed modelling programs in a regulatory context. Journal of Building Performance Simulation 1(4), 209-219.

Loga, T., Diefenbach, N., Stein, B. (edited by). (2012). Typology Approach for Building Stock Energy Assessment. Main results of the TABULA project. Institut Wohnen und Umwelt GmbH. Darmstadt.

Michalak, P. (2014). The simple hourly method of EN ISO 13790 standard in Matlab/Simulink: A comparative study for the climatic conditions of Poland. Energy 75, 568-578.

Millet, J.-R. (2007). The simple hourly method of prEN 13790: a dynamic method for the future. Proceedings from Clima 2007 WellBeing Indoors. Helsinki (Finland), $10^{\text {th }}-14^{\text {th }}$ June.

Van Dijk, D., Spiekman, M., Hoes-van Oeffelen, L. (2016). EPB standard EN ISO 52016: Calculation of the building's energy needs for heating and cooling, internal temperatures and heating and cooling load. REHVA Journal 53(3), 18-22. 